
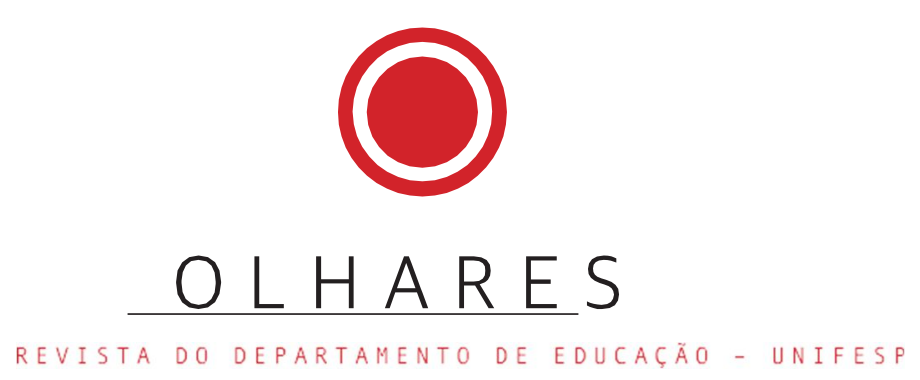

\title{
"A NOSSA HISTÓRIA PODE SER CONTADA" - Um relato sobre alfabetização em círculos de cultura em Nazaré (RO)
}

\author{
"OUR STORY CAN BE TOLD" - A report about literacy in culture circles in \\ Nazaré (RO)
}
"NUESTRA HISTÓRIA PUEDE SER CONTADA" - Um relato sobre alfabetización em círculos de cultura en Nazaré (RO)

Helen Cristiane da Silva Theodoro Universidade Federal de São Carlos helenstheodoro@gmail.com

Michele Cristina Batista Barbado Centro Universitário Salesiano de São Paulo michelebbarbado@gmail.com

Sophia Ricci Noronha Fundação Getulio Vargas sophia.ricci.noronha@hotmail.com

Valéria Oliveira de Vasconcelos Centro Universitário Salesiano de São Paulo Valvasc2013@gmail.com

Resumo: A desigualdade social é uma das mais fortes marcas do Brasil, mantendo grupos segregados e hierarquizados, seja por razões econômicas, étnicas, raciais, de gênero, de sexualidade e até por seus níveis de escolarização. $O$ analfabetismo persiste em nosso país e coincide quase exatamente com a geografia da pobreza. Frente a este contexto, o presente artigo traz o relato de uma vivência com mulheres ribeirinhas cuja história, segundo uma delas: "pode ser contada". A experiência foi realizada na comunidade de Nazaré, localizada no baixo Rio Madeira/RO, na Amazônia brasileira e ocorreu no âmbito das ações do Núcleo de Apoio às Populações Ribeirinhas da Amazônia - NAPRA. Este artigo apresenta o relato de um trabalho cujo objetivo foi o de desenvolver encontros pedagógicos com vistas à alfabetização de algumas mulheres adultas. A metodologia foi pautada nos círculos de cultura segundo o referencial freiriano. Como resultados são apontados quatro aprendizados principais: 1) a importância de estar, de forma genuína, no território onde os encontros acontecem; 2) a necessidade de articulação regional-local e da permanência para o êxito das atividades; 3) a importância do processo como gerador de potencialidades coletivas e individuais; 4) o entendimento de que, mesmo a experiência sendo pontual, pode gerar mobilização, possibilidade concreta de transformação e partilhas amorosas. Importante ressaltar que, a Amazônia tem sido foco de graves ameaças sociais e ambientais, sendo reduzida a histórias de conflito e violência. Porém, há muitas narrativas a serem compartilhadas e sempre é possível ter esperança quando conseguimos contar outra história.

Palavras-chave: Educação Popular. Diálogo. Participação. 
Resumen: La desigualdad social es una marca fuerte de Brasil. El mantenimiento de la segregación se extiende a través de líneas económicas, étnicas, raciales, de género, sexuales e incluso educativas. El analfabetismo persiste y coincide casi exactamente con la geografía de la pobreza. Frente este contexto, este artículo presenta un relato basado en un compromiso y un diálogo con las mujeres ribereñas a través del cual, según una de ellas, su historia "se puede contar." La experiencia se llevó a cabo en la comunidad de Nazaré, ubicada en el bajo Río Madeira / RO, en la Amazonía brasileña, como parte de las acciones del Centro de Apoyo a Poblaciones de Ribera de la Amazonía (NAPRA). El objetivo del trabajo fue desarrollar encuentros pedagógicos con la intención de iniciar la alfabetización de las mujeres ribereñas. La metodología se basó en círculos culturales según el marco freiriano. Como resultado, se señalan cuatro lecciónes principales: 1) la importancia de estar arraigado en el territorio donde se desarrollan los encuentros; 2) la necesidad de la articulación regional-local para el éxito de las actividades; 3) la importancia del proceso como generador de potencial colectivo e individual; 4) la comprensión de que, aunque la experiencia sea puntual, puede generar transformación y el compartir amoroso. Es importante destacar que la Amazonía ha sido el foco de graves amenazas socioambientales, reduciéndose a historias de violencia. Sin embargo, hay muchas historias que compartir y siempre es posible tener esperanza cuando somos capaces de contar otro cuento.

\title{
Palabras clave: Educación Popular. Diálogo. Participación.
}

\begin{abstract}
Social inequality is a strong mark of Brazil. The maintenance of segregation and hierarchal groups is extended through economic, ethnic, racial, gender, sexual, and even educational lines. Illiteracy persists and coincides almost exactly with the geography of poverty. Faced with this context, this article presents a report drawing on engagement and dialogue with riverside women through which according to one of them: their story "can be told". The experience was carried out in the community of Nazaré, located on the lower Rio Madeira/RO, in the Brazilian Amazon and took place within the scope of the actions of the Support Group for Riverside Populations in the Amazon (NAPRA). The objective was to develop pedagogical meetings with the intent to onset the literacy of adult riverside women. The methodology was based on culture circles according to the Freirian framework. As a result, four main lessons are pointed out: 1) the importance of being genuinely rooted in the territory where the meetings take place; 2 ) the need for regional-local articulation for the success of activities; 3 ) the importance of the process as a generator of collective and individual potential; 4) the understanding that, even if the experience is punctual, it can generate transformation and lovingly sharing. It is important to note that the Amazon has been the focus of serious socioenvironmental threats, being reduced to stories of violence. However, there are a lot of narratives to be shared and it is always possible to hope when we are able to tell another story.
\end{abstract}

Keywords: popular Education. Dialogue. Participacion. 


\section{Introdução}

O Rap é a comunidade enchendo a laje É ir no cinema ver um filme e tá lá o Sabotage É quando um moleque da Fundação contraria

Quem diria, ganha um concurso de poesia

É uma chave, um escudo, uma espada Uma lâmpada, um colete, uma escada Uma bússola, um despertador

O Rap é Milton Santos, é Paulo Freire, é escola Tem uns que estuda e outros que só cola É família que vira freestylera Improvisa com pouco dentro da geladeira

Um pivetinho ouvindo Racionais com 11 anos A força de uma senhora se alfabetizando.

(INQUÉRITO. Lição de Casa. 2018')

Paulo Reglus Neves Freire (1921 - 1997) se alfabetizou sob as árvores no quintal de sua própria casa. Riscando o chão ia formando as letras, com a ajuda da mãe, aos poucos foi entendendo, os símbolos e seus significados. Assim, como ele mesmo relatou: "fui alfabetizado no chão do quintal de minha casa, à sombra das mangueiras, com palavras do meu mundo e não do mundo maior dos meus pais. O chão foi o meu quadro-negro; gravetos, o meu giz" (FREIRE, 1989, p. 11).

Desse modo, compreende-se que o ato de ler e escrever precisa ter significado na vida: correr, plantar, colher, brincar, trabalhar. As palavras codificadas devem ganhar sentido para que o sujeito aprenda sua realidade e possa decodificar esses sinais gráficos. "A leitura do mundo precede a leitura da palavra, daí que a posterior leitura desta não possa prescindir da continuidade da leitura daquele. Linguagem e realidade se prendem dinamicamente" (FREIRE, 1989, p. 9).

Ler o mundo é algo que se aprende desde a mais tenra idade. Para ler o mundo, muito do conhecimento é adquirido oralmente, passado de geração em geração, e se modifica com o tempo. Já o universo letrado, dentro de um determinado idioma, requer uma aprendizagem técnica, seja em casa ou na escola. Freire (1989) discorre sobre como saber ler e escrever pode ser includente ou excludente, tanto que saber escrever garante ao ser vivente uma série de benefícios, além de contribuir para uma autoestima valorizada.

1 INQUÉRITO. Lição de Casa. Independente. 2018. Duração: 4'25". Disponível em: https://onerpm.Ink.to/LicaoDeCasa. 
Freire (1989), relatou sobre seu árduo trabalho para diminuir o índice de analfabetismo adulto, em uma tentativa de apoiar futuros/as profissionais da educação, deixando claro seu posicionamento de não neutralidade. Para o autor: "o que temos de fazer, então, enquanto educadoras ou educadores, é aclarar, assumindo a nossa opção, que é política, e sermos coerentes com ela, na prática" (FREIRE, 1989, p. 16). Agregando a este posicionamento, Vasconcellos (2010) esclareceu que:

A persistência do analfabetismo é um dos indicadores mais significativos da desigualdade política, socioeconômica e cultural, limitando o valor essencial da dignidade humana. A presença de analfabetismo se associa sempre a situações de subdesenvolvimento, marginação ou isolamento. [...] A geografia do analfabetismo vem a coincidir quase exatamente com a da pobreza, com escassas exceções (TORRADO, 1991, p. 51, apud VASCONCELOS et. al, 2010, p. 55).

Respectivamente a isso, a desigualdade social é, infelizmente, uma das mais fortes marcas brasileiras. Por esse motivo, mantêm segregados grupos e os coloca à margem da sociedade, seja por razões econômicas, étnicas, raciais, de gênero, de orientações sexuais, e até mesmo por seus níveis de escolarização (ROSADO; FERNANDES, 2013; JEFFREY; LEITE, 2016).

Tamanha desigualdade se expressa também entre os Estados da Federação, sendo que a média de rendimento familiar é menos da metade nas regiões Norte e Nordeste em comparação com Sul e Sudeste (IBGE, 2020). É nesse contexto que a experiência do presente artigo está inserida, o qual relata a vivência de três integrantes ${ }^{2}$ de uma organização não-governamental (ONG) em uma comunidade ribeirinha na Amazônia, no ano de 2018, com a alfabetização de adultos por meio da abordagem freiriana.

A intenção de escrever o presente relato de experiência surgiu a partir da provocação de uma das mulheres ribeirinhas participantes do projeto de alfabetização. Durante uma das inúmeras conversas ocorridas na vivência, ela afirmou: - "A nossa história pode ser contada". Depois de três anos da realização do projeto, a vontade de compartilhar essa potente vivência se manteve, o que trouxe as escritoras do presente relato até aqui, agora.

Para isso, além dessa introdução o texto segue com uma seção sobre o contexto amazônico, em que será abordado brevemente sobre a história e características mais amplas da região. A próxima seção é destinada ao desbravamento da história da comunidade de Nazaré, foco do presente relato. Posteriormente, a seção seguinte trata

\footnotetext{
${ }^{2}$ As três primeiras autoras participaram da experiência in loco. A quarta autora é membro do Conselho Consultivo da mesma ONG e contribuiu para a escrita e aprofundamento teórico desse relato.
} 
sobre as ações sociais desenvolvidas na comunidade. Dando sequência, a próxima seção discorre sobre o relato de experiência como um todo, trazendo detalhamentos em subseções, sendo: encontros de formação e continuidade do projeto. Ao final serão expostas as considerações finais da experiência.

\section{O contexto amazônico}

A comunidade foco do presente estudo localiza-se na região Norte do país que, segundo Maciel (2014), passou por inúmeras mudanças bem diferentes daquelas dos demais estados. Não tendo a cana-de-açúcar como elemento colonizador, outros ciclos econômicos modificaram a realidade local e sua cultura, fazendo com que a região amazônica se transformasse em três principais momentos: "o colonial, o do seringal e o da urbanização da cultura cabocla" (MACIEL, 2014, p. 101).

Mais especificamente, se tratando do Estado de Rondônia Souza (2011) faz um relato histórico em relação à formação e constituição desse Estado. Para isso, o autor considerou sua cultura, fauna, flora e a discordância de toda a beleza em relação ao ciclo da borracha, que agiu de forma impactante o Estado de Rondônia, modificando a realidade local. A destruição em massa pela derrubada da floresta para o pasto, a invasão do garimpo e as madeireiras que insistem em tornar este o Estado mais desmatado da floresta amazônica.

Candido (2010), esclareceu que a formação social atual da região amazônica foi produzida a partir de migrações com um grande desequilíbrio entre o número de homens e mulheres. Isso, impedia a formação de núcleos familiares entre os/as migrantes, fazendo com que mulheres indígenas fossem incorporadas, geralmente de forma violenta, às sociedades dos seringais. De certa forma, a mulher indígena acabou compartilhando seu profundo saber sobre a floresta, subsidiando o aprendizado dos seringueiros e, assim, formando em conjunto uma cultura e forma de vida peculiares.

Com o final do ciclo da borracha, tendo muitas famílias já constituídas, os seringueiros não retornaram mais às suas cidades de origem. Estando "libertos" dos patrões, eles passaram a morar em locais próximos aos seringais, o que deu origem ao que se nomeia atualmente de "comunidades ribeirinhas". Essas comunidades continuaram a viver da borracha, da castanha e do extrativismo, da caça e pesca e da agricultura em pequena escala, em que tudo era comercializado com barqueiros que passavam pelas suas 
regiões - conhecidos como "regatões". (ALENCAR, 2012; CANDIDO, 2010; MENEZES, 2014).

As comunidades se estenderam por toda a região de rios que circulam dentro da floresta Amazônica. Na região de Porto Velho, essas populações estão distribuídas ao longo do rio Madeira, um dos principais rios da bacia Amazônica, cujos modos de vida são assegurados como tradicionais, conforme Decreto 6.040 de 7 de fevereiro de 2007 (BRASIL, 2007). Sendo fruto e a continuidade da história local e nacional, as comunidades seguiram ao longo das décadas preservando sua cultura. Porém, essa permanência acontece em meio a conflitos relacionados à terra, recursos naturais e ao seu modo de vida.

\section{Nazaré: desbravando sua história}

Nazaré é uma comunidade tradicional localizada à beira do Rio Madeira, distrito na zona rural do município de Porto Velho/RO (130 km à jusante da capital do Estado) e pode ser acessada somente por via fluvial, devendo ser percorridas em média, de 8 a 10 horas de barco. Historicamente, teve sua formação a partir de "Seu Nanã", seringalista que, como muitos outros, concedia os instrumentos aos seringueiros para a coleta da seringa, disponibilizava moradia, alimentação e outros itens necessários. Conta-se que a entrada do igarapé Peixe-Boi - até então, chamado "boca do furo" - foi cavado por seus funcionários, para que se tivesse melhor acesso à água. Seu Nanã já faleceu, mas sua esposa, filho e amigos ainda viviam na comunidade no momento da vivência relatada (CANDIDO, 2010; FIGUEIREDO; SEVERINO, 2018; MACIEL, 2014; SOUZA, 2011).

A comunidade é classificada como uma área de assentamento do Instituto Nacional de Colonização e Reforma Agrária - INCRA, e o órgão responsável por sua gestão, em Nazaré, é a Empresa de Assistência Técnica e Extensão Rural - EMATER. A área do assentamento fica ao longo dos dois bairros, chamados de "lado de dentro" e "lado de fora" (denominação informal atribuída pelos/as moradores/as em função de sua maior ou menor proximidade com o Rio Madeira) (CANDIDO, 2010; FIGUEIREDO; SEVERINO, 2018; MACIEL, 2014; SOUZA, 2011). 
Figura 1 - Vista do centro comunitário localizado na "área de dentro"

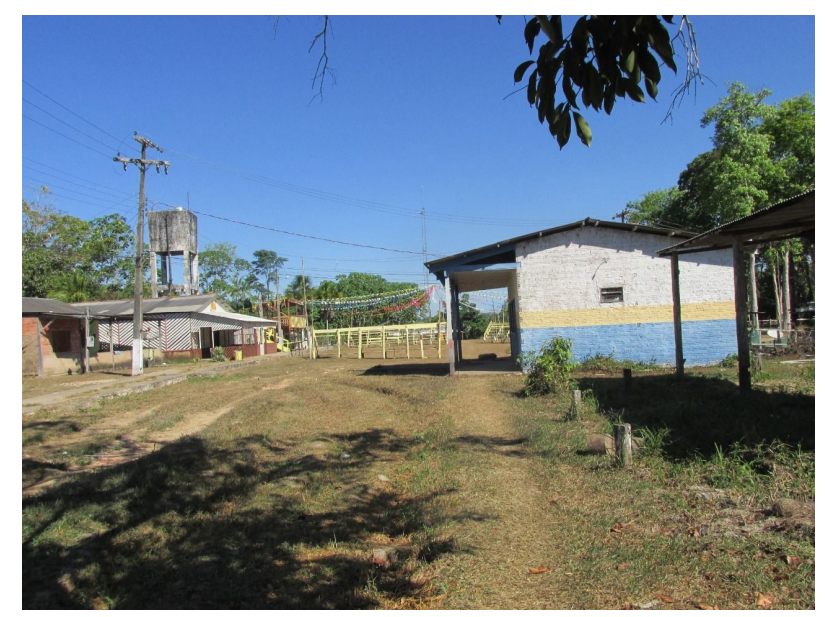

Fonte: Arquivo pessoal das autoras.

Na foto acima, é possível ver o centro comunitário, localizado na "área de dentro", onde os encontros ocorreram. Respectivamente, o que se sabe é que a comunidade possui muitos casos de analfabetismo e de pessoas semianalfabetas (FIGUEIREDO; SEVERINO, 2018). Esse fator, se dá pelo fato de que as escolas (municipal e estadual), estão instauradas na comunidade há cerca de 10 anos, fazendo com que os/as moradores/as não tivessem acesso à educação formal anteriormente a este período (CANDIDO, 2010; FIGUEIREDO; SEVERINO, 2018).

Outro fator a ser considerado é que, comumente, a união conjugal ocorre quando alguns/umas jovens ainda estão na fase escolar, dificultando que terminem os estudos. Além disso, desde muito cedo as crianças são designadas para o trabalho braçal, em que os meninos acompanham os pais no garimpo e as meninas acompanham as mães na lavoura e/ou ficam responsáveis por cuidarem da casa e das/os irmãs/os mais novas/os sozinhas, o que gera uma grande evasão escolar (MACIEL, 2014; SOUZA, 2011).

Apesar da dificuldade de acesso e das propostas educacionais não condizerem necessariamente com a realidade da comunidade, sabe-se que a escrita tem um valor importante nas relações sociais. Ela representa um tipo de status, instrumentaliza o indivíduo para que possa se movimentar na sua localidade, participar de reuniões, escrever mensagens, manipular documentos etc. (VALDANHA NETO; WHITAKER; VASCONCELOS, 2018, p. 57). Muito além da função técnica, poder escrever as próprias palavras é uma forma de gerar identidade e se colocar no mundo. Nesse sentido, o processo de se educar, segundo Freire, é um exercício de mergulho na realidade, em que se dá sentido à vida e aos atos cotidianos (FREIRE, 2016). 
Vale ressaltar o quanto a visão de Freire (1989) pode ser levada não só para o ensino de adultos, mas das próprias crianças do território. Meninos e meninas que tinham muita dificuldade na escola eram julgadas/os por brincarem fora de casa o dia inteiro, mas aos poucos mostravam, através desse brincar, autoras/es de grandes proezas. Como descrito no diário de campo das autoras, sobre um dos meninos da comunidade:

[...] ele e os irmãos têm muita dificuldade na escola, ficam o dia inteiro fora de casa brincando [...] mas fomos percebendo muitas potências. O mais novo, a esperteza e a mira. O mais velho, o jeito com foto. Mas a escola nunca vai saber disso (DIÁRIO DE CAMPO, 2018).

Tais experiências e habilidades dos meninos, tão distantes e subvalorizadas pela escola, demonstram como a educação escolar, muitas vezes, deixa de lado uma parte fundamental da vida e do aprendizado: a descoberta do mundo. O saber da leitura e da escrita ampliam o universo de compreensão, mas não devem ter hierarquia em relação a outros saberes, e a depender da necessidade, do contexto, ler e escrever pode ser mais ou menos importantes que saber andar na floresta.

De acordo com Valdanha Neto, Whitaker e Vasconcelos (2018), ao reportarem-se à educação escolar de crianças residentes na Reserva Extrativista Lago do Cuniã, localizada na mesma região do Baixo Madeira:

\begin{abstract}
Importante salientar na "educação na floresta" (fora da escola) a presença de diversos saberes empíricos, contextualizados no meio de vida e não mediatizados pela escola. Eles são, em geral, invisibilizados, desconsiderados ou negligenciados pela instituição escolar (VALDANHA NETO; WHITAKER; VASCONCELOS, 2018, p. 57)
\end{abstract}

Essa realidade também está presente em Nazaré, em que muitos conhecimentos não são contemplados pela escola. Nessa perspectiva, a educação se torna algo distante e, muitas vezes, sem sentido. Como abordado por Freire (1989, p. 10), "já não é possível texto sem contexto". 


\section{Atuações sociais em Nazaré}

A comunidade de Nazaré tem apoio, no mês de julho, de duas ONGs ${ }^{3}$. A experiência aqui relatada está atrelada ao Núcleo de Apoio à População Ribeirinha da Amazônia NAPRA ${ }^{4}$.

Durante quase uma década, o NAPRA funcionou como projeto de extensão, atuando com equipes de cerca de 40 integrantes (que se renovavam quase completamente todos os anos). Essas equipes eram compostas, sobretudo, por estudantes e profissionais da área de saúde e nesse período, as ações foram expandidas para diversas outras comunidades dispersas ao longo de 200 km do Rio Madeira, entre os municípios de Porto Velho/RO e Humaitá/AM.

Gradativamente, estudantes e profissionais de diversas universidades do Estado de São Paulo, de diferentes áreas de conhecimento (engenharias, pedagogia, medicina, educação especial, psicologia, dentre outros), foram se associando ao NAPRA, que passou a se organizar em quatro regionais localizadas nas cidades de São Paulo, Campinas, São Carlos e Catanduva, todas pertencentes ao Estado de São Paulo. A atuação nas comunidades ribeirinhas passou a ser construída, então, de forma interdisciplinar, o que se mantém até a atualidade.

Como explicitado, esse relato trata da experiência de quatro integrantes do NAPRA, sendo uma da área da Educação Especial, duas da área da Pedagogia e uma da Administração Pública. A interdisciplinaridade proposta pela ONG, bem como os conhecimentos e vivências das integrantes em diferentes áreas, tanto educacional quanto política, e principalmente as formações anteriores à viagem resultaram na experiência aqui relatada.

É importante ressaltar a ênfase dada pelo NAPRA nas formações dos voluntários. Antes de realizarem as viagens, o grupo participa de formações mensais durante sete meses, sendo: sobre o contexto amazônico, processos produtivos na floresta, particularidades de povos tradicionais e métodos de atuação no território. O conteúdo é dividido em eixos temáticos: saúde, trabalho, cultura e educação. Todas as formações têm base na Educação Popular e têm o propósito de preparar os voluntários para que não

\footnotetext{
3 Uma delas tem o atendimento voltado à saúde, realizando atendimentos médicos e odontológicos aos comunitários gratuitamente (Doutores sem Fronteiras).

${ }^{4}$ Mais informações: https://napra.org.br/.
} 
reproduzam formas coloniais de intervenção. Por isso, as formações são profundamente transformadoras para aqueles que as experienciam, fazendo com que, muitas das vezes, voluntários deem continuidade em suas vidas acadêmicas e profissionais trabalhando com projetos relacionados aos temas abordados pelo NAPRA.

Os anos de experiência do NAPRA resultaram em alguns aprendizados que hoje guiam os rumos da organização. Compreendeu-se que a missão da organização não estava apenas relacionada ao fortalecimento das comunidades de Rondônia, mas a atuação vinha contribuindo significativamente à formação dos/as associados/as e ao estímulo para seu engajamento em questões socioambientais. Para potencializar esses resultados, nos últimos anos a ONG tem buscado estruturar e ampliar esse processo de formação.

Outra mudança importantíssima se refere às estratégias utilizadas pela organização na intervenção comunitária. A experiência acumulada e o contato com a literatura sobre Educação Popular mostraram que, para uma atuação efetivamente comprometida com a transformação social, os projetos desenvolvidos não poderiam partir das demandas da ONG, eles deveriam partir das demandas dos/as moradores/as do Baixo Madeira.

O papel do NAPRA, portanto, como o nome da organização aponta, deveria ser o de dar apoio e potencializar os projetos das comunidades. Por isso, atualmente, todas as ações são pautadas em um princípio básico: os/as moradores/as das comunidades parceiras devem ser protagonistas dos projetos, exercendo suas condições de agentes e se engajando na construção do seu próprio futuro (NAPRA, 2020).

\section{Relatando a experiência}

No ano de 2018, muitas foram as ações realizadas pela equipe do NAPRA em Nazaré. Em razão de julho ser um mês festivo para a comunidade, pois é quando ocorre o Festival Cultural de Nazaré com a festa do Boi Bumbá, algumas atividades foram direcionadas a essa finalidade. As demais ações foram realizadas junto aos/aos moradores/as ao longo de todo o mês, sendo elas: Oficina de fotografia; Oficina de resíduos do festejo cultural; Oficina sobre convivência e autocuidado; Oficina de saúde; Oficina de macramê, Oficina de contação de histórias e a Oficina de alfabetização de adultos. Essa última, se pautou no referencial freireano de alfabetização de adultos, tendo como base introdutória os Círculos de Cultura com o intuito de compreender, fortalecer e preservar a cultura local dessa comunidade ribeirinha na Amazônia (FREIRE, 1967; 1989). 
Buscando identificar pessoas interessadas em participar do nosso projeto de alfabetização de adultos, a primeira ação foi a de realizar visitas de porta em porta divulgando a proposta e explicando o que seria feito. Foram dedicados dois dias para essa etapa, nos quais foram visitadas cerca de 50 casas. Para a visita, as autoras contaram com a participação de um representante da Escola Municipal, devido sua proximidade com a população local. Dentre todas as pessoas convidadas, onze mostraram interesse ${ }^{5}$, sendo dez do sexo feminino e um do sexo masculino.

Além do objetivo de identificar e convidar as pessoas para as oficinas de alfabetização, a visita nas casas era um processo muito importante de reconhecimento de mundo e construção de vínculos.

Passando pelas casas, às vezes timidez, sempre muita simpatia. Na casa do Z.F., ele falou "é bom quando vem gente de longe, traz muita poesia. Quanto mais longe, mais poesia. E, daqui, leva poesia também". Ele é um dos mais velhos da comunidade, semianalfabeto e ex-seringueiro. (Diário de campo, 2018).

Todos os encontros ocorreram no espaço comunitário/biblioteca, localizado em uma região de fácil acesso para os moradores.

Figura 2 - Espaço comunitário, local das oficinas

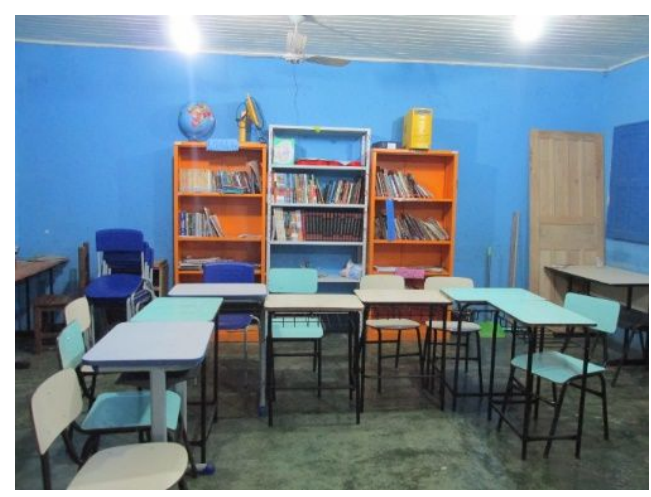

Fonte: arquivo das autoras

\footnotetext{
${ }^{5}$ Provavelmente o número de pessoas interessadas seria maior se esse levantamento fosse realizado com mais tempo. Conforme observações na comunidade: "Os adolescentes e mulheres são tímidos e difíceis de chegar junto, em comparação com as crianças. Mas o silêncio não significa necessariamente desinteresse. Tem que saber sentir" (Diário de campo, 2018).
} 
O primeiro encontro foi agendado para o dia 16 de julho, em que compareceram quatro mulheres ${ }^{6}$ : Isabel, Joana, Mariele (não alfabetizadas) e Frida (semialfabetizada). Inicialmente, foram marcados oito encontros com duração de uma hora e meia cada, com o objetivo de intensificar esse processo de ensinar-e-aprender inicial (BRANDÃO, 2014), uma vez considerando o limite temporal das atividades da ONG como um todo.

\section{Encontros de formação}

A intervenção comunitária é, geralmente, uma ação que demanda tempo para aproximação, para o amadurecimento conjunto do planejamento e uma reflexão aprofundada sobre os caminhos a seguir. Neste aspecto, Vasconcelos (2002) esclareceu que:

[...] o conhecimento na Educação Popular não é algo que deva ser depositado por um grupo de detentores do saber a outro que não o possui. A prática educativa deve inferir em um processo de intervenção em que os distintos saberes - o saber popular e os do educador - se contrapõem e se complementam. O conhecimento, portanto, seria elaborado através desse processo mútuo de intercâmbio entre saberes. (VASCONCELOS, 2002, p. 57)

Ocorre que esse processo não se dá sem contradições. Assim, inicialmente as responsáveis pela oficina optaram por atuar dentro dos moldes da pedagogia tradicional: apresentando o alfabeto, suas letras e fonologia.

Deve-se levar em consideração que as responsáveis pelo projeto estavam em estágios iniciais de formação profissional e com pouco conhecimento prático na área. Porém, a vontade de fazer mais e de forma significativa fez com que buscassem na formação "napriana" as bases da Educação Popular. Sendo assim, buscaram encontrar significado a signos que antes poderiam passar despercebidos. Foi o ensinar-e-aprender entrando em ação, e a busca em referencial teórico freiriano já incorporado das autoras para que a oficina ganhasse novos rumos.

Depois desse momento, passaram a atuar com base nos Círculos de Cultura (FREIRE, 1967), nos quais não existem relações hierarquizadas entre professoras/es e alunas/os, mas pessoas que aprendem juntas pelo diálogo a partir de palavras-geradoras.

\footnotetext{
${ }^{6}$ Com o intuito de manter o sigilo e privacidade das participantes, foram escolhidos nomes fictícios de mulheres que marcaram a história nacional e internacional, como forma de homenagem por mudarem suas histórias de vida, consequentemente de suas famílias e a das voluntárias.
} 
Esta forma de ensinar, foi selecionada por ser muito potente ao contribuir para gerar autonomia e desenvolvimento coletivo, e faz sentido para a alfabetização de adultos. Desse modo, uma vez que a comunicação por meio da fala já está consolidada, ela se torna o fundamento para os aprendizados. Cada encontro foi planejado objetivando um ensino dinâmico e participativo, que fosse embasado em discussões e no compartilhamento de saberes por todas as pessoas presentes.

Foram realizados exercícios de ortografia, pontuação, utilização de alfabeto escrito e móvel, construção silábica simples, uso de livro de poesias e contos disponíveis no espaço comunitário. Ao final de cada encontro, eram elaborados exercícios para que as alunas pudessem refletir sobre as oficinas, para além dos momentos em que estas aconteciam.

Partiu-se da premissa que "enquanto objetos de conhecimento, os conteúdos se devem entregar à curiosidade cognoscitiva de professores e alunos. Uns ensinam e, ao fazê-lo, aprendem. Outros aprendem e, ao fazê-lo, ensinam" (FREIRE, 1992, p. 112).

Todo o processo se mostrou profundamente educativo, mesmo reconhecendo que, por vezes, as voluntárias ainda estavam em fase de aprofundamento em pesquisas e iniciando seus conhecimentos nas reflexões freirianas. Por outro lado, Freire ensina que "ninguém caminha sem aprender a caminhar, sem aprender a fazer o caminho caminhando, refazendo e retocando o sonho pelo qual se pôs a caminhar" (FREIRE, 1992, p. 155).

A proposta de alfabetização pautada em Freire está centrada principalmente no diálogo e na participação. Consequentemente, as educadoras foram inserindo diferentes dinâmicas no Círculo de Cultura como descrito por Freire (1967), buscando respeitar esse pressuposto central, cujo objetivo são as trocas por meio de uma relação horizontal, respeitosa e que permita que os envolvidos possam participar ativamente. Para além disso, Freire (2016) esclareceu:

\footnotetext{
Educador e educandos (liderança e massas), co-intencionados à realidade, se encontram numa tarefa em que ambos são sujeitos no ato, não só de desvelá-la e, assim, criticamente conhecê-la, mas também no de recriar este conhecimento. Ao alcançarem, na reflexão e na ação em comum, este saber da realidade, se descobrem como seus refazedores permanentes. Deste modo, a presença dos oprimidos na busca de sua libertação, mais que pseudo-participação, é o que deve ser: engajamento (FREIRE, 2016).
}

Deste modo, as atividades realizadas encontro a encontro serão detalhadas a seguir. No início das oficinas, cada uma das participantes se apresentou, falando o nome e porque tinha vontade de estudar. Também foi conversado como se daria a dinâmica dos encontros, 
discutindo a proposta de aprendizado a partir da valorização da cultura. Além disso, foram firmados alguns acordos, sendo eles: a) não poder rir do erro do outro; b) ter postura cooperativa com as outras mulheres; c) valorizar todos os saberes e pessoas igualmente; d) evitar faltas por conta do período curto de oficinas; d) comunicar sempre que houver qualquer problema; e, e) cuidar do material.

Durante o primeiro encontro, foi apresentado o alfabeto, suas vogais e consoantes, em letra bastão, reforçando-se a parte fonética e a grafia das letras. As participantes chegaram ao encontro com certa timidez, ainda com dúvidas de qual dinâmica seria realizada e como se dariam com a escrita. Ao longo do encontro, iniciou-se a construção de um ambiente seguro, de cuidado e de valorização coletiva. Ao final, todas se mostraram animadas com a perspectiva de aprendizado da forma como foi proposto.

No segundo encontro, as voluntárias retornaram ao ensino e aprendizagem do alfabeto iniciando com as formações silábicas, fruto da junção entre vogais e consoantes. A partir desse momento, foi possível analisar e acompanhar o aprendizado das participantes Joana, Mariele e Isabel, que aprenderam o alfabeto com facilidade e entenderam perfeitamente o processo silábico.

Todas as participantes já tinham contato com símbolos gráficos por conta do mundo letrado em que vivemos. Por isso, o alfabeto não era necessariamente uma novidade para elas. As mulheres conheciam o universo das palavras, mas naquele momento iniciavam seu percurso no caminho de entendimento e da junção das letras e palavras. Foi possível perceber durante os encontros que, a partir dos ensinamentos propostos por Freire (1967), as comunitárias participaram ativamente das discussões por meio dos temas trabalhados e sentiam-se confortáveis para mostrar o que sabiam ou não sabiam.

No terceiro encontro estavam presentes todas as alunas, inclusive Frida. $O$ acompanhamento da aluna Frida foi realizado por uma voluntária com formação em pedagogia. A voluntária detectou que a aluna já estava no nível alfabético-ortográfico, fase em que o sujeito sabe codificar e decodificar as letras. No momento de registrar ainda apresentava dificuldades nas regras de ortografia e gramática da língua portuguesa, para ler a aluna demonstrou dificuldade em compreender parte do que lia. Com esta informação, foi trabalhado em todas as aulas a leitura de um conto escolhido por Frida, depois da leitura era realizada uma roda de conversa para entendimento e interpretação oral dos contos e a partir do próprio conto eram ensinadas e efetuadas as seguintes revisões: pontuação; acentuação; regras de ortografia e gramática. 
Com as demais alunas, a partir do quarto encontro foi inserido um passo-a-passo dos Círculos de Cultura, adaptado a partir das leituras de Freire (1967, p. 111-119), que oportunamente foi resumida e escalonada para este estudo da seguinte forma:

1) Levantar o universo vocabular presente no contexto das participantes para que fossem usadas palavras que gerassem discussões relevantes e que fossem facilmente relacionadas com uma imagem conhecida. Isso se deu em duas etapas:

a) Olhar sobre distintos conteúdos que emergem das expressões e dos falares típicos, trazendo palavras ligadas à experiência, com riqueza semântica e fonética;

b) Identificar questões latentes para as participantes.

2) Diferenciar os níveis de dificuldade das palavras.

3) Apresentar uma imagem ou objeto que representasse o significado da palavra e discutir um tema relacionado a esta palavra.

4) Apresentar a palavra escrita e fazer a divisão silábica.

5) Criar a "Ficha de Descoberta", que consiste em usar as consoantes da palavra com todas as vogais e criar fonemas.

6) As participantes copiam essa construção no caderno e tentam, individualmente, fazer novas palavras com as sílabas aprendidas. É a etapa de exploração autônoma da Ficha de Descoberta.

7) Compartilhar as palavras com o grupo todo.

O processo descrito no item 1 é elucidado pela imagem a seguir:

Figura 3 - Palavras geradoras de Nazaré

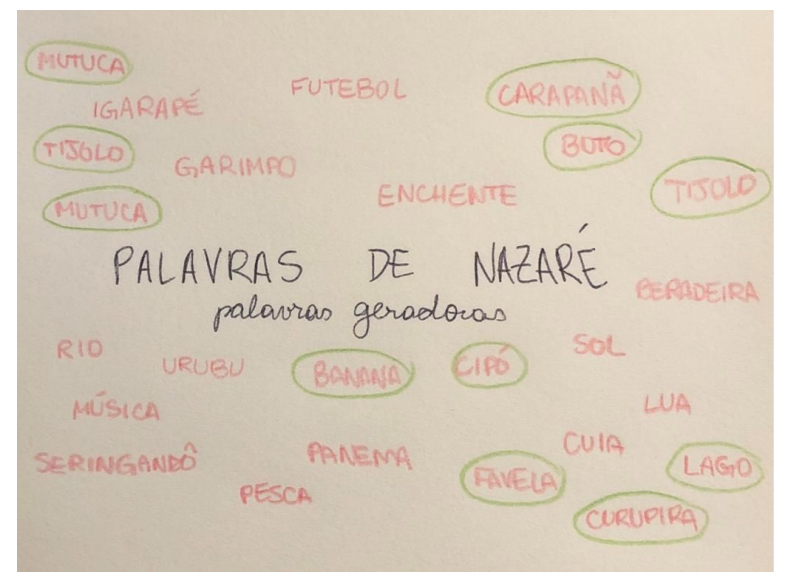

Fonte: Diário de campo, 2018. 
As palavras foram definidas a partir da escuta em campo na comunidade, priorizadas a depender do tipo de discussão que poderia gerar e do seu nível de dificuldade. As palavras circuladas em verde, na imagem acima, foram as escolhidas para iniciar o processo, uma vez que cumpriam esses três requisitos (FREIRE, 1967).

O círculo de cultura se iniciou com palavras mais simples, cujas sílabas tinham apenas uma consoante e uma vogal, e depois foi aumentando a complexidade. Exemplo: ti-jo-lo / mu-tu-ca / be-le-za (nível 1); i-ga-ra-pé / ju-li-e-ta (nível 2); de-si-gual-da-de / cul-tura / mi-lho / li-mão (próximos níveis).

No caso da palavra "cultura", foi iniciada a discussão (item 3 da metodologia) com as seguintes perguntas disparadoras: "o que é cultura?"; "Qual a importância de preservála?"; "Quais as manifestações culturais daqui?". Em todo o processo buscou-se deixar espaço para elas discutirem entre si e incentivando a elaboração de argumentos, sendo nosso papel o de agentes facilitadores. Nesse ponto, foi trazida a importância da cultura de cada território como forma de gerar identificação entre as pessoas e seus modos de vida.

Utilizou-se em seguida a palavra "beleza". Como meio de interação inicial, foi solicitado que uma aluna falasse para a outra o que achava bonito nela. Posteriormente, discutiu-se padrões de beleza e racismo. Todas se divertiram ao elogiarem e serem elogiadas, trazendo leveza e felicidade para o encontro. Em outro momento, foi usada a palavra "igarapé" para discutir a abundância da floresta em contraste com a cidade, local de moradia das voluntárias.

No que diz respeito aos itens 4 e 5 foram utilizadas palavras e realizada a construção silábica a partir delas. Exemplo: ti-jo-lo >> ta/te/ti/to/tu - ja/je/ji/jo/ju - la/le/li/lo/lu. Foi realizada a leitura das sílabas de forma coletiva e depois a leitura na vertical e na horizontal (tatetitotu / tajala...).

Dando sequência, no item 6, no caso da Ficha de Descoberta de "tijolo", formaram as palavras: tatu, laje, luta, lata, jato, tititi, jiló. Neste momento, foi enfatizada a importância da palavra luta, que as mulheres relacionaram com trabalhar, resistir e não desistir, ir atrás dos ideais e lutar por uma educação de qualidade.

A partir da quarta aula, Joana, Mariele e Isabel passaram a ir ao quadro para escreverem e compartilharem as palavras que tinham escrito de forma independente, o que foi gerador de motivação tanto para as alunas quanto para as facilitadoras do projeto. Nas alunas, notou-se, por meio de observação da conduta e postura das participantes, um enorme ganho na autoestima e na formação de suas identidades. Se antes não falavam por algum receio, agora iam até a lousa e se sujeitavam a mostrar erros e acertos, sendo 
uma forma de se verem realizando novas atividades com maestria, gerando novas reflexões sobre suas potências e possibilidades. $O$ ato de escrever as próprias palavras, em pouco tempo, gerou sentimentos de ânimo e alegria em todas as mulheres do grupo.

A fim de desafiá-las, as educadoras buscaram outras palavras com um nível de maior dificuldade, em forma de ditado. Esta atividade contribuiu para que as mulheres trabalhassem a percepção sonora, separando palavras em sílabas e depois refletindo sobre a escrita para saber quais letras que a compõem. Ouvindo cada sílaba, transformavam o som em escrita.

A participante Frida demonstrou grandes avanços com disposição para realizar as atividades e interesse por conhecer um pouco mais. Ao final foi realizado um exercício de revisão em que foram apresentados os conteúdos trabalhados anteriormente, como forma de reforçar o conhecimento. Isabel, Joana e Mariele também apresentaram visível progresso na elaboração de discussões e na formação das palavras. Com o avanço dos encontros, as mulheres conseguiram descobrir novas palavras e realizar a sua leitura.

Nesta perspectiva, é sabido que no mundo letrado saber ler e escrever é uma forma de gerar dignidade. Contribui a esse posicionamento Esperança Garcia, mulher negra escravizada, que escreveu em 1770 uma petição que denunciava as situações de violência que ela e sua comunidade passavam, pedindo retratação do governador da Capitania. Hoje, ela é reconhecida como a primeira advogada do estado do Piauí e em uma de suas escritas, transcrita no livro de Sonia Rosa (2012), ela retratou sobre o aprendizado da leitura e da escrita.

\footnotetext{
O meu bem mais precioso foi aprender a ler e escrever. Este aprendizado me ajudou a compreender melhor o mundo e a me indignar com as injustiças e com os horrores da escravidão. Saber ler e escrever é uma maneira de esticar, bem esticada, a voz da gente, fazendo com que ela chegue a tempos e a lugares distantes, nunca imaginados. (GARCIA, 1770; apud ROSA, 2012)
}

Refletindo sobre isso, acredita-se que cada pessoa é única e, respeitando essas diferenças, as participantes do projeto se desenvolveram cada qual no seu tempo. No início, todas venceram o primeiro obstáculo - o receio da aproximação, venceram o cansaço do dia trabalhado e foram para um ambiente em que lhes colocava a proposta de aprender a ler a palavra a partir de sua leitura de mundo.

Por conta do comprometimento das mulheres ribeirinhas, foi possível observar rápidos avanços e, com isso, a segurança e autoestima das participantes e das voluntárias também. À medida que todas se entregavam às atividades, foram transformando 
insegurança em respeito mútuo. Partiu-se sempre da junção dos saberes das mulheres da comunidade e dos saberes das voluntárias, gerando partilhas e troca conjuntas.

As voluntárias almejaram atender as especificidades de cada aluna, dentro de suas potencialidades e limitações. A proposta foi criar relações de maneira horizontal, na tentativa de potencializar a participação de todas, sendo que a construção da autonomia e independência nas alunas é parte primordial do processo na Educação Popular. No entanto, é essencial pontuar que a horizontalidade pretendida enquanto educadoras perpassa dificuldades, devido ao desequilíbrio de privilégio considerando o recorte de raça, classe e região, entre voluntárias e comunitárias. É inegável que existia uma disparidade de poder de quem pode propor uma nova atividade, de quem pode "ensinar", de quem pode falar, e assim por diante.

\section{Continuidade do projeto}

Uma das preocupações ao longo do processo foi a continuidade do projeto na comunidade, pois o excelente desempenho das alunas e o grande interesse delas em continuar estudando mostrava o quanto esse projeto era importante. Para tanto, as educadoras buscaram a formação de parcerias que pudessem atuar voluntariamente no projeto. As/os representantes das escolas Municipal e Estadual se mobilizaram e ficou acordado que, após a saída das facilitadoras da comunidade, as aulas seriam ministradas pela vice-diretora da escola estadual, com o auxílio dos demais representantes das escolas envolvidas.

Após a volta dos voluntários do NAPRA para o Estado de São Paulo, a comunicação com as comunitárias se tornou mais desafiadora. Em dado momento de 2019, uma das professoras relatou que as oficinas continuavam, que as mulheres estavam avançando e que todas prestariam o Exame Nacional para Certificação de Competências de Jovens e Adultos - ENCCEJA, para obterem o diploma de Ensino Fundamental.

Apesar do relativo sucesso das atividades, dificilmente trabalhos pontuais conseguem desenvolver as articulações necessárias para a continuidade do projeto a longo prazo. Ainda ocorrem inquietações, em como é possível superar tais dificuldades com projetos que são desenvolvidos por pessoas que residem muito longe dos espaços de atuação. "É justo a gente trazer um monte de ideia e quem tem que levar isso para frente depois serem eles próprios? Qual combinado temos pré-existente disso?" (DIÁRIO DE CAMPO, 2018). Complementando a isso, Vasconcelos (2002), esclarece que: 
Segundo Jara (1994) a Educação Popular implica um processo de certa duração, uma vez que somente um acompanhamento a longo prazo permitirá a percepção mais analítica das conquistas e dificuldades enfrentadas nas situações particulares e sua consequente retroalimentação. Além disso, atividades pontuais correm o risco de representar formas paliativas de enfrentar as injustiças sociais e, por conseguinte, de reforçar a manutenção do status quo, alimentando estereotipias de que, se a realidade não muda, é porque a própria população não colabora. Como se doses homeopáticas pudessem solucionar problemas crônicos da sociedade; a realidade enfrentada pela população foi construída no decorrer de gerações e acreditar que um trabalho de duração tão reduzida poderia conduzir efetivamente a uma transformação social é perigosamente ingênuo (VASCONCELOS, 2002, p. 182).

As provocações de Vasconcelos (2002) se relacionam com inquietações que já estavam presentes durante as atividades de intervenção, como ilustrado nesse trecho do diário de campo:

Encontros, igarapé, ritmos - é difícil ser de fora, ser turista, e conseguir criar vínculos nesse espaço novo e diferente. Dá para ver o quanto a rotatividade do NAPRA prejudica a atuação, além da distância de tempo entre uma viagem e outra. Me mostra a importância de trabalhos locais com parcerias locais para essa troca. Por isso seria tão importante que o NAPRA fizesse parcerias aqui em volta, com as lideranças daqui e da região. (DIÁRIO DE CAMPO, 2018)

Fica claro, portanto, a importância de articulação local para aprofundamento das ações desenvolvidas e da sua continuidade. Esse movimento foi feito, na medida do possível, no caso da experiência relatada, mas aponta a necessidade de mudança estrutural na coordenação de atividades socioambientais dentro de organizações como NAPRA.

\section{Considerações finais}

O objetivo deste artigo foi relatar as experiências vivenciadas por educadoras, aprendizes do processo de alfabetização via Círculos de Cultura, pautadas nas obras freirianas. Para além de toda vivência, ficou evidente que alguns desacertos foram cometidos, no entanto muitos aprendizados se fizeram presentes a partir deles, sendo desafiador reconhecer as dinâmicas do espaço, compreender profundamente os valores e modos de vida particulares do território. No entanto, foi a partir do fazer, da experiência, que se espera contribuir, possivelmente, para aprendizados coletivos na Educação Popular. 
Se Paulo Freire, em toda sua trajetória, já pedia que nós nos reinventássemos e reinventássemos sua prática, o fazer das voluntárias e o aprendizado mútuo entre todas as sete mulheres tem o seu valor como processo educativo. A troca de afetos, sendo afeto a capacidade de nos afetarmos pelo/a outro/a, estava presente em cada instante da prática. Como educadoras em formação, as voluntárias foram profundamente afetadas por essa experiência, e o desejo de escrever sobre ela se manteve por anos.

A Educação Popular se mostrou muito poderosa, gerando um aprendizado integral, coletivo e impulsionador de coragem. O processo educativo popular resgata dignidade, leva as pessoas a se sentirem sujeitas da sua própria realidade e intervirem nela, e assim como disposto por Freire (1967) "a consciência crítica é a representação das coisas e dos fatos como se dão na existência empírica, nas suas relações causais e circunstanciais".

Foram identificados quatro aprendizados principais da prática realizada. O primeiro é sobre a importância de estar, de forma genuína, no território onde os encontros acontecem. Isso significa estar aberto a afetar e ser afetado, a colaborar, compartilhar e entender a não neutralidade da atuação, sendo todos sujeitos ativos do processo. Conforme aponta o diário de campo: "Estar presente é entender o momento das coisas, das falas, dos toques. Estar presente é se aterrar e os sonhos partirem desse lugar" (DIÁRIO DE CAMPO, 2018).

O segundo aprendizado é sobre a necessidade de articulação regional-local e da permanência para o êxito das atividades. É essencial compreender mobilizações próprias do território e colaborar com ações já em vigor e coordenadas por movimentos sociais, lideranças locais e outras organizações da região. Assim, é possível realizar ações que são parte de projetos mais amplos e contínuos, que têm responsabilidade com as histórias das pessoas e respeito com os vínculos construídos.

O terceiro aprendizado é sobre a relevância do processo. A importância da vivência coletiva está para além dos resultados que alcança, mas principalmente no processo, que é gerador de potencialidades coletivas e individuais. A principal mudança que os grupos, como é o caso dos círculos de cultura, são capazes de gerar é de como os próprios participantes se reconhecem - e isso é irreversível. Os participantes se apropriam de sua memória, sua identidade, reinventam seus costumes e suas convicções e essa reelaboração de identidade se traduz, a longo prazo, em todas as relações com o mundo na família, no trabalho, entre outros - e pode, então, gerar mudanças profundas.

O quarto aprendizado é perceber como uma experiência pontual pode gerar tantas mobilizações internas e externas e representar possibilidades concretas de transformação 
e de partilhas amorosas. Identificou-se nos pequenos detalhes do fazer coletivo a humanidade e a potência presente em cada uma. A força não estava na tristeza, nas dificuldades e desafios superados, mas principalmente no ânimo, na criatividade e na ternura.

Diante do exposto, finaliza-se o presente artigo tomando emprestado uma frase de uma peça sobre Rosa Luxemburgo, que esteve presente na mente das voluntárias durante a atuação em campo: "Eu também sou, como você sabe, uma terra de possibilidades ilimitadas" (DIÁRIO DE CAMPO, 2018).

Nazaré é uma terra de possibilidades ilimitadas, assim como todos/as nós. A Amazônia tem sido foco de graves ameaças sociais e ambientais, sendo reduzida a histórias de conflito e violência. No entanto, há muitas outras narrativas possíveis e é a partir de projetos que potencializam vozes e vidas do território que podem se compartilhar novas histórias, denunciando o que está ocorrendo e anunciando outras possibilidades. É sempre possível esperançar quando contamos outra história (KRENAK, 2019).

\section{Referências}

ALENCAR, Carolina Pena de. Trilhando memórias: reflexões acerca das identidades dos trabalhadores da Estrada de Ferro Madeira-Mamoré. 137 f. Dissertação (Mestrado em Preservação do Patrimônio Cultural). Instituto do Patrimônio Histórico e Artístico Nacional. Rio de Janeiro/RJ. 2012. Disponível em: http://portal.iphan.gov.br/uploads/publicacao/estrada_de_ferro.pdf. Acesso em: 25 jun. 2021.

BRANDÃO, Carlos Rodrigues. Paulo Freire: a educação, a cultura e a universidade. Memória de uma história de cinquenta anos atrás. Revista EJA EM DEBATE, Florianópolis, ano 3, n. 4. jul. 2014.

BRASIL. Decreto-lei $\mathbf{n}^{\circ}$ 6040, de 7 de fevereiro de 2007. Institui a Política Nacional de Desenvolvimento Sustentável dos Povos e Comunidades Tradicionais. Lex: coletânea de legislação: edição federal, São Paulo, 1943. Disponível em: < http://www.planalto.gov.br/ccivil_03/_ato2007-2010/2007/decreto/d6040.htm> Acesso em: 31 junho 2021.

CANDIDO, Sílvio Eduardo A. Comunidades ribeirinhas, engenheiros e conservação da floresta: construção participativa do espaço tecnológico em empreendimentos econômicos solidários na Amazônia. 195f. Dissertação (Mestrado em Engenharia de Produção). Programa de Pós-Graduação em Engenharia de Produção da Universidade Federal de São Carlos - UFSCar. São Carlos/SP. 2010. Disponível em: https://repositorio.ufscar.br/bitstream/handle/ufscar/3638/3170.pdf?sequence=1\&isAllowed =y. Acesso em: 10 dez. 2018. 
CRUZ, Adejard Gaia. Dois séculos de extrativismo e especialização primário-exportadora na Amazônia: uma análise comparada entre os ciclos da borracha e do minério de ferro. Cadernos CEPEC, vol. 08, nº 01, jun., 2019, p. 43-66. Disponível em: https://periodicos.ufpa.br/index.php/cepec/article/view/7764. Acesso em: 15 mai. 2021.

FIGUEIREDO, Rafaela Lopes; SEVERINO, Natália Búrigo. Boi Curumim de Nazaré: um estudo sobre a cultura popular tradicional de uma comunidade ribeirinha. XI Encontro Regional Sudeste da Associação Brasileira de Educação Musical Educação Musical em tempos de crise: percepções, impactos e enfrentamentos. São Carlos/SP, p. 1-14, 2018. Disponível em:

http://abemeducacaomusical.com.br/conferencias/index.php/sd2018/regsd/paper/viewFile/ 3213/1766. Acesso em: 22 mai. 2021.

FREIRE, Paulo. Educação como Prática da Liberdade. Rio de Janeiro/RJ, Ed. Paz e Terra, 1967.

A importância do Ato de Ler. São Paulo/SP, Cortez Editora, 1989. 104

p.

Pedagogia da Esperança: um reencontro com a Pedagogia do Oprimido. Rio de Janeiro/RJ, Paz e Terra, 1992.

Pedagogia do Oprimido. $60^{\circ}$ ed. Rio de Janeiro/RJ, Paz e Terra, 2016. 288

p.

INQUÉRITO. Lição de Casa. Independente. 2018. Duração: 4'25”. Disponível em: https://onerpm.Ink.to/LicaoDeCasa. Acesso em: 29 jul. 2021.

IBGE. Instituto Brasileiro de Geografia e Estatística. Síntese de Indicadores Sociais: uma análise das condições de vida da população brasileira de 2016. Rio de Janeiro/RJ, vol.36, 2016 2016. V. 36, 141 p. Disponível em:

https://biblioteca.ibge.gov.br/visualizacao/livros/liv98965.pdf. Acesso em: 22 jun. 2021.

JEFFREY, Debora Cristina; LEITE, Sandra Fernandes. Qualidade de ensino na modalidade EJA sob a perspectiva dos docentes. Olhares: Revista Do Departamento De Educação Da Unifesp, vol. 04, nº 01, mai. 2016, p. 8-26. Disponível em:

https://periodicos.unifesp.br/index.php/olhares/article/view/525/171. Acesso em: 15 mai. 2021.

KRENAK, Ailton. Ideias para adiar o fim do mundo. Nova edição. Editora Companhia das Letras, 2019.

MACIEL, Antônio Carlos. Identidade e diversidade na formação cultural da Amazônia: estudo comparativo entre Belém, Manaus e Porto Velho. In: GHANEM, E; NEIRA, M. G. Educação e Diversidade Cultural no Brasil - Ensaios e Práticas. Organizadores:

GHANEM, Elie; NEIRA, Marcos; $1^{\text {a }}$ ed., Araraquara/SP, Junqueira \& Marin, 2014, 271 p.

MAIOR. Nível de Escolaridade Está Associado a Maior Expectativa de Vida. Faculdade de Medicina da Universidade Federal de Minas Gerais - UFMG, 2019. Disponível em: 
https://www.medicina.ufmg.br/maior-nivel-de-escolaridade-esta-associado-a-maiorexpectativa-de-vida/. Acesso em: 31 jul. 2021.

MENEZES, Elisangela Ferreira. A representação do lugar: um estudo sobre juventude ribeirinha da comunidade de Nazaré-RO. 136 f. Dissertação (Mestrado em Geografia). Universidade Federal de Rondônia. Porto Velho/RO. 2014. Disponível em: https://core.ac.uk/download/pdf/294854238.pdf. Acesso em: 25 jun. 2021.

NAPRA. Núcleo de Apoio à População Ribeirinha da Amazônia. Consolidação do Estatuto Social. 5a Alteração do Estatuto Social. Disponível em: https://drive.google.com/file/d/1SZeic_PVxBVLF3mLPInXJKrqvbhoFcJF/view. Acesso em: 02 abr. 2021.

ROSA, Sonia. Quando a escrava Esperança Garcia escreveu uma carta. Pallas, 2012.

ROSADO, Andrea da Conceição Cândido; FERNANDES, Cássia do Carmo Pires. Políticas e concepções de Educação de Jovens e Adultos: fundamentos da prática docente. Olhares: Revista Do Departamento De Educação Da Unifesp, vol. 01, $\mathrm{n}^{\circ} 02$, 2013, p. 180-192. Disponível em: https://periodicos.unifesp.br/index.php/olhares/article/view/139. Acesso em: 22 jun. 2021.

SOUZA, Valdir Aparecido. Rondônia, uma memória em disputa. 202f. Tese (Doutorado em História e Sociedade). Universidade Estadual Paulista "Júlio de Mesquita Filho" UNESP. Faculdade de Ciências e Letras. Programa de Pós-Graduação em História e Sociedade. Assis/SP. 2011. Disponível em:

https://repositorio.unesp.br/bitstream/handle/11449/103127/souza_va_dr_assis.pdf?seque nce=1. Acesso em: 10 dez 2018.

VALDANHA NETO, Diógenes; WHITAKER, Dulce Consuelo Andreatta; VASCONCELOS, Valéria Oliveira de. Educação $\mathrm{e}(\mathrm{m})$ Unidades de Conservação: luta por direitos e direito à luta. Rev. Ed. Popular, Uberlândia, v. 17, n. 2, p. 51-67, mai/ago. 2018. Disponível em: http://www.seer.ufu.br/index.php/reveducpop/article/view/41518. Acesso em: 15 jul. 2021.

VASCONCELOS, Valéria Oliveira de. Bebendo em uma fonte de Água Fresca caminhos para a formação de agentes comunitários de lazer. 331f. Tese (Doutorado em Educação) Universidade Federal de São Carlos. Centro de Educação e Ciências Humanas. Programa de Pós-Graduação em Educação. São Carlos/SP. 2002. Disponível em: http://www.bdae.org.br/dspace/handle/123456789/318. Acesso em: 25 mai. 2021.

VASCONCELOS, Valéria Oliveira de; SIQUEIRA, Cristiano Tierno de; SANTOS, Raquel; SALAZAR, Marcelo; STRAATMANN, Jeferson; NEVES, Letícia; REIS, Allan Ribeiro dos; \& CAMPOS, Patrícia Greco. Educação Popular e meio ambiente: diálogos com populações tradicionais amazônicas. Ambiente \& Educação, vol. 15, nº 01, 2010, p. 4766. Disponível em: https://periodicos.furg.br/ambeduc/article/view/879. Acesso em: 08 jun. 2021.

Recebido em: 09/08/2021

Aceito em: 25/10/2021 